\title{
Lip and Oral Cavity Cancer cN2a TNM Finding v8
}

National Cancer Institute

\section{Source}

National Cancer Institute. Lip and Oral Cavity Cancer cN2a TNM Finding v8. NCI

Thesaurus. Code C132714.

Lip and oral cavity cancer with metastasis in a single ipsilateral lymph node larger than 3

$\mathrm{cm}$ but not larger than $6 \mathrm{~cm}$ in greatest dimension and ENE(-). (from AJCC 8th Ed.) 